\title{
Risk factors for neurodevelopmental impairments in school-age children after cardiac surgery with full-flow cardiopulmonary bypass
}

\author{
Michael von Rhein, MD, ${ }^{\text {a,b }}$ Anastasia Dimitropoulos, MD, ${ }^{\mathrm{a}}$ Emanuela R. Valsangiacomo Buechel, MD, ${ }^{\mathrm{c}}$ \\ Markus A. Landolt, $\mathrm{PhD},{ }^{\mathrm{d}}$ and Beatrice Latal, $\mathrm{MD}, \mathrm{MPH}^{\mathrm{a}, \mathrm{e}}$
}

Objective: To determine the risk factors for adverse neurodevelopmental outcomes in school-age children after full flow open-heart surgery for congenital heart disease.

Methods: The outcome was assessed in 117 children without a genetic comorbidity at a mean age of $10.4 \pm 2.5$ years. Intelligence was assessed using the Raven's Progressive Matrices and neuromotor function using the Zurich Neuromotor Assessment. Risk factors were retrieved from detailed chart review.

Results: The mean intelligence score was $89 \pm 16$, significantly lower than the norm $(P<.001)$. Cerebral palsy was diagnosed in $10 \%$ of patients. Poor neuromotor performance (less than p10) was present in $15 \%$ to $20 \%$ of the children, depending on the motor task (all $P<.001$ ). Pure motor and static balance performance was also significantly impaired when patients with cerebral palsy were excluded $(P<.01)$. Intelligence was only related to socioeconomic status $(P=.006)$, and neuromotor outcome was related to the length of hospital stay and postoperative neurologic abnormalities $(P<.03)$. The extracorporeal circulation time was related to adaptive fine motor performance $(P=.05)$. All other variables were not related to outcome.

Conclusions: Children without a genetic comorbidity are at risk of long-term intellectual and motor impairments also after full-flow cardiac repair. Surgery-related parameters play a less important role for adverse outcomes than postoperative complications. Our findings stress the importance of specialized follow-up assessments for all children with CHD undergoing open heart surgery. (J Thorac Cardiovasc Surg 2012;144:577-83)

Children undergoing open heart surgery for severe congenital heart disease (CHD) are at risk of neurodevelopmental impairments. These have been related to the surgical technique (eg, circulatory arrest). ${ }^{1}$ Thus, a variety of studies have focused on the significance of perioperative and surgical factors. ${ }^{1-3}$ It is of note that the risk factors could differ depending on the treatment and bypass protocols. ${ }^{4,5}$ To date, only 1 study has examined the neurodevelopmental outcomes of patients who underwent solely full flow cardiopulmonary bypass. Karl and colleagues ${ }^{4}$ demonstrated, in a population of children undergoing surgery for transposition of the great arteries, that neurodevelopmental outcome was impaired at 8 years of age. In addition, evidence has shown that, independent of surgical technique, the intellectual outcome can be affected. ${ }^{5,6}$ Neurodevelopmental deficits

\footnotetext{
From the Child Development Center, ${ }^{a}$ Children's Hospital, Zurich, Switzerland; Department of Pediatric Neurology, ${ }^{\text {b }}$ University Children's Hospital, Mainz, Germany; Department of Pediatric Cardiology, ${ }^{\mathrm{c}}$ University Children's Hospital, Zurich, Switzerland; Department of Psychosomatics and Psychiatry, ${ }^{\mathrm{d}}$ University Children's Hospital, Zurich, Switzerland; and Center for Integrative Human Physiology, ${ }^{\mathrm{e}}$ University of Zurich, Zurich, Switzerland.

The study was supported by the Mercator Foundation Switzerland, Swiss Heart Foundation, and Else Kröner-Fresenius-Stiftung.

Disclosures: Authors have nothing to disclose with regard to commercial support.

Received for publication Sept 15, 2011; revisions received Jan 9, 2012; accepted for publication Feb 3, 2012; available ahead of print March 12, 2012.

Address for reprints: Michael von Rhein, MD, Child Development Center, University Children's Hospital of Zurich, Steinwiesstrasse 75, Zurich CH-8032 Switzerland (E-mail: Michael.vonrhein@kispi.uzh.ch).

$0022-5223 / \$ 36.00$

Copyright (c) 2012 by The American Association for Thoracic Surgery doi:10.1016/j.jtcvs.2012.02.005
}

have mostly been described for infants and patients up to early school age. ${ }^{1,4,5,7}$ Thus, knowledge is lacking regarding the outcomes at later school ages and in adolescence. Furthermore, much of the data have focused on the highest risk patients (eg, hypoplastic left heart syndrome or transposition of the great arteries). ${ }^{1,4,5,7,8}$ It is unanswered to what extent the knowledge on neurodevelopmental impairments in patients with hypoplastic left heart syndrome or transposition of the great arteries is applicable to patients with less severe CHD. In addition, it is unclear whether the risk factors that have been identified for early neurodevelopmental impairments remain the same for longterm problems. ${ }^{4}$ Furthermore, because patient-specific factors such as genetic comorbidities ${ }^{5}$ or a genetic polymorphism ${ }^{9}$ have been identified as critical factors for adverse outcomes, the risk factors for the long-term outcomes in children without a genetic comorbidity need to be better examined.

Therefore, the aim of our study was to describe the longterm neurodevelopmental outcomes in a cohort of 117 Swiss children without a known or suspected genetic comorbidity who all underwent full-flow cardiopulmonary bypass surgery. Furthermore, we aimed to determine the relevance of risk factors for the long-term neurodevelopmental outcomes.

\section{METHODS \\ Subjects \\ We included all children with CHD who underwent their first corrective heart surgery with full-flow cardiopulmonary bypass at the University}




\section{Abbreviations and Acronyms \\ $\mathrm{CHD}=$ congenital heart disease \\ $\mathrm{ZNA}=$ Zurich Neuromotor Assessment}

Children's Hospital of Zurich from 1995 to 1998, and who spoke sufficient German to complete the questionnaires $(\mathrm{n}=200)$. Patients with chromosomal abnormalities $(n=31)$ or genetic syndromes $(n=12)$, and patients with neurologic comorbidities not associated with heart disease or surgery (1 each congenital rubella and neurofibromatosis) were excluded. Screening for genetic comorbidities was performed by an experienced pediatric attending physician (B.L.) using a standardized checklist for syndromal stigmata or malformations. A total of 155 children were eligible. Three families were lost to follow-up, and 32 families refused to participate, 5 because of the severe mental disabilities of their child. Three CHD patients could not be tested because their severe motor or mental disabilities did not allow a standardized assessment. The final sample therefore comprised 117 children (response rate, $75.4 \%$ ) who were assessed from October 2004 to July 2006. Children lost to follow-up did not differ from the study group regarding age at surgery $(P=.40)$, gender $(P=.67)$, socioeconomic status $(P=.13)$, diagnosis of cyanotic CHD $(P=.54)$, age at first surgery $(P=.36)$, number of operations $(P=.70)$, duration of cardiopulmonary bypass $(P=.30)$, or length of hospital stay $(P=.36)$. The cardiac diagnoses are listed in Table 1 . None of the participating adolescents had a history of birth asphyxia or extreme immature birth. Only 1 child was born with a birth weight of $940 \mathrm{~g}$, with an uncomplicated postnatal course; all others had a birth weight greater than $1500 \mathrm{~g}$.

The Ethics Committee of the University Children's Hospital Zurich approved the present study. The parents were informed about the study and provided written informed consent.

\section{Procedure and Risk Factors}

The patients underwent surgery using a uniform intention-to-treat strategy involving a cardiopulmonary bypass flow of $150 \mathrm{~mL} / \mathrm{kg} / \mathrm{min}$, with an $\alpha$-stat $\mathrm{pH}$ strategy during hypothermia. Circulatory arrest was avoided when possible, except for the period required to close the atrial septal defect (occurred in 10 patients, median, 6 minutes; range, 3-27). Hemoglobin was maintained at 8 to $9 \mathrm{~g} / \mathrm{dL}$ during cardiopulmonary bypass, and fresh heparinized (noncitrated) blood was used in the cardiopulmonary bypass circuit prime. We also used precardiopulmonary bypass blockade with phenoxybenzamine and a single dose of methylprednisolone in the priming solution. Cardiopulmonary bypass was exclusively established with aortic and right atrial cannulation.

A large number of potential risk factors were retrieved from the patients' records and parental interviews to determine their association with outcome. Theses included birth, cardiac, and peri- and intraoperative variables (Tables 1 and 2). All patients were neurologically assessed after surgery by the house officer in charge. Electroencephalographic (EEG) recordings were performed if clinically indicated. The socioeconomic status was calculated using a 6-point scale of both paternal occupation and maternal education and ranged from 2 (lowest) to 12 (highest). ${ }^{10}$ This is a validated socioeconomic status classification in Switzerland. ${ }^{11}$ The median socioeconomic status was 8 (range, 2-12).

\section{Neurodevelopmental Outcome Assessment}

The neurodevelopmental assessment was performed at the Child Development Center. General intelligence was tested using the Raven Progressive Matrices. ${ }^{12}$ This nonverbal intelligence test assesses abstract reasoning and analytical intelligence and corresponds better to performance than the verbal intelligence quotient (IQ) test. ${ }^{13}$ The reference values were based on the German norm. A standardized neurologic examination was performed and classified according to severity, ranging from
TABLE 1. Birth and cardiac characteristics of sample $(n=117)$

\begin{tabular}{|c|c|}
\hline Characteristic & Value \\
\hline \multicolumn{2}{|l|}{ Birth weight (g) } \\
\hline Median & 3205 \\
\hline Range & $940-4300$ \\
\hline \multicolumn{2}{|l|}{ 5-min Apgar score } \\
\hline Median & 9 \\
\hline Range & $7-10$ \\
\hline Male gender (n) & $66(56)$ \\
\hline Premature birth (n) & $9(8)$ \\
\hline Emergency cesarean section (n) & $23(20)$ \\
\hline Prenatal diagnosis of CHD (n) & $6(5)$ \\
\hline Family history of CHD (n) & $38(32)$ \\
\hline \multicolumn{2}{|l|}{ CHD type (n) } \\
\hline Noncyanotic & $67(57)$ \\
\hline Atrial septal defect, ventricular septal defect & 46 \\
\hline Aortic stenosis & 9 \\
\hline Aortic coarctation & 4 \\
\hline Cor triatriatum & 2 \\
\hline Shone complex & 2 \\
\hline Pulmonary stenosis & 2 \\
\hline Coronary fistula & 1 \\
\hline Mitral valve stenosis & 1 \\
\hline Cyanotic & $50(43)$ \\
\hline Tetralogy of Fallot & 14 \\
\hline Transposition of the great arteries & 12 \\
\hline Pulmonary atresia & 8 \\
\hline Double inlet left ventricle & 8 \\
\hline Total anomalous pulmonary venous connection & 3 \\
\hline Tricuspid atresia & 2 \\
\hline Atrioventricular canal & 2 \\
\hline Truncus arteriosus & 1 \\
\hline
\end{tabular}

Data in parentheses are percentages. $C H D$, Congenital heart disease.

mild to severe (mild, abnormalities in muscle tone or tendon reflexes; moderate, abnormalities in tone and stretch reflexes but without cerebral palsy; and severe, cerebral palsy). ${ }^{14}$ Cerebral palsy was classified according to the European guidelines. ${ }^{14}$ The reference values for the prevalence of cerebral palsy were determined from recently published rates in Europe. ${ }^{15}$

Neuromotor performance was examined using the Zurich Neuromotor Assessment (ZNA). The ZNA is a standardized procedure for assessing specific motor tasks in regard to the speed (timed performance) and quality of movement. ${ }^{16}$ Test-retest, and interobserver and intraobserver reliability have been established, and gender- and age-related normative values (percentiles) are available. ${ }^{17}$ The battery of tests includes the assessment of pure motor tasks (repetitive, alternating, and sequential movements), adaptive fine (pegboard), and adaptive gross (dynamic balance) motor tasks, static balance, and stress gaits. Some motor tasks (static and dynamic balance) present increasing difficulties in performance, depending on the child's age. The child's performance was videotaped. The motor performance was timed with a stopwatch, and this timed performance was then summarized into standard components: pure motor tasks and adaptive fine motor, adaptive gross motor, and static balance components. Of the 12 children with cerebral palsy, 9 could be assessed using the ZNA.

The Raven's Progressive Matrices and ZNA was administered by 1 trained study nurse, and the neurologic and medical examination was performed by 1 developmental pediatrician (B.L.). Both were unaware of the severity of CHD and the clinical course. Educational career and support and rehabilitation services were documented by completing standardized interview questionnaires. 
TABLE 2. Perioperative characteristics of sample $(n=117)$

\begin{tabular}{|c|c|}
\hline Variable & Value \\
\hline \multicolumn{2}{|l|}{ Age at first surgery (y) } \\
\hline Median & 1.1 \\
\hline Range & $0-8.7$ \\
\hline \multicolumn{2}{|l|}{ Weight at surgery $(\mathrm{kg})$} \\
\hline Median & 8.9 \\
\hline Range & $2.2-27.3$ \\
\hline \multicolumn{2}{|l|}{ Lowest preoperative oxygen saturation $(\%)$} \\
\hline Median & 90.0 \\
\hline Range & $48-100$ \\
\hline \multicolumn{2}{|l|}{ Duration of extracardial circulation (min) } \\
\hline Median & 92.0 \\
\hline Range & $27-206$ \\
\hline \multicolumn{2}{|l|}{ Duration of aortic crossclamping (min) } \\
\hline Median & 41.0 \\
\hline Range & $6-117$ \\
\hline \multicolumn{2}{|l|}{ Minimal intraoperative temperature $\left({ }^{\circ} \mathrm{C}\right)$} \\
\hline Median & 26.0 \\
\hline Range & $16-37$ \\
\hline \multicolumn{2}{|l|}{ Minimal postoperative $\mathrm{pH}$} \\
\hline Median & 7.33 \\
\hline Range & $7.08-7.44$ \\
\hline \multicolumn{2}{|l|}{ Length of stay in intensive care unit (d) } \\
\hline Median & 6 \\
\hline Range & $1-95$ \\
\hline \multicolumn{2}{|l|}{ Length of hospital stay (d) } \\
\hline Median & 15 \\
\hline Range & $6-129$ \\
\hline \multicolumn{2}{|l|}{ Total number of surgical operations } \\
\hline Median & 1.3 \\
\hline Range & $1-4$ \\
\hline More than 1 surgery (n) & $23(20)$ \\
\hline Preoperative cardiac insufficiency (n) & $45(38)$ \\
\hline Cardiac arrest (n) & $10(9)$ \\
\hline Open thorax after surgery (n) & $16(14)$ \\
\hline \multicolumn{2}{|l|}{ Postoperative complications (n) } \\
\hline Arrhythmia & $33(28)$ \\
\hline Reintubation & $11(10)$ \\
\hline Resuscitation & $9(8)$ \\
\hline $\begin{array}{l}\text { Postoperative EEG anomalies or focal } \\
\text { neurologic symptoms (n) }\end{array}$ & $19(16)$ \\
\hline
\end{tabular}

For patients with multiple operations, duration of extracardial circulation and aortic crossclamping reflected total times for all operations; lowest preoperative oxygen saturation, minimal intraoperative temperature, and postoperative $\mathrm{pH}$ represent lowest values for all operations. Data in parentheses are percentages. EEG, Electroencephalographic.

\section{Statistical Analysis}

The data were analyzed using Statistical Package for Social Sciences, statistics software, version 19 (SPSS, Stanford, Calif). Univariate analyses were conducted using the Spearman correlation test to determine the predictors associated with the outcomes and to verify co-linearity among variables. A stepwise linear (for continuous outcome variables) or logistic (for dichotomous outcome variables) regression analysis was then conducted, including variables that correlated with 1 of the outcome variables on univariate analysis with $P<.05$. Because of the rather small sample size, we used a second model in which we included a choice of variables that had been reported to be risk factors for adverse outcomes in published
TABLE 3. Neurodevelopmental outcome for children with CHD $(\mathbf{n}=117)$

\begin{tabular}{lccc}
\hline \multicolumn{1}{c}{ Intelligence } & Patients & $\begin{array}{c}\text { Normal } \\
\text { value* }\end{array}$ & $\boldsymbol{P}$ value \\
\hline RPM standard score & & & \\
$\quad$ Mean, SD & $89.4(16.2)$ & $100(15)$ & $<.001$ \\
$<85, \%(\mathrm{n})$ & $35(41)$ & 15.8 & $<.001$ \\
$<70, \%(\mathrm{n})$ & $6(7)$ & 2.2 & $<.001$ \\
ZNA & & & \\
Pure motor $<$ p10 & $18(15)$ & 10 & $<.001$ \\
Adaptive fine motor $<$ p10 & $20(17)$ & 10 & $<.001$ \\
Adaptive gross motor $<$ p10 & $24(21)$ & 10 & $<.001$ \\
Static balance $<$ p10 & $23(20)$ & 10 & $<.001$ \\
Cerebral palsy & $12(10)$ & $0.01 \%$ & $<.001$ \\
\hline
\end{tabular}

Statistics: 1-sided $t$ test and chi-square tests compared with norm. CHD, Congenital heart disease; $R P M$, Raven's Progressive Matrices; $S D$, standard deviation; $Z N A$, Zurich Neuromotor Assessment. *References values are based on the distribution of standard scores in the standardization samples ${ }^{12,16}$ and on literature on the prevalence of cerebral palsy ${ }^{15}$; scores $<85$ or $<70$ for IQ and $<10$ th percentile for motor performance are given only in percentages.

studies, ${ }^{5,18,19}$ although they had not correlated with the outcomes in our univariate analysis: cyanotic CHD, preoperative blood oxygen saturation, postoperative arrhythmias, and postoperative resuscitation.

The study sponsors are independent foundations, dedicated to supporting clinical research. No sponsor had influence on the study design, the collection, analysis, and interpretation of data, or the writing of the report and the decision to submit it for publication.

\section{RESULTS}

The mean patient age at assessment was $10.4 \pm 2.5$ years (range, 6.5-16.8). The patient characteristics and CHD distribution are listed in Table 1 and the perioperative variables in Table 2. Nine children were born prematurely; however, none was born before 32 weeks of gestation, and no child had a history of birth asphyxia. At surgery, $45 \%$ of patients were younger than 1 year. We observed deficits in intellectual and neuromotor outcome (Table 3). These problems corresponded to the need for educational support: $23 \%$ of the patients with CHD were enrolled in a 2-year, first grade program, $13 \%$ required special education, and $27 \%$ required speech and language therapy. Children who needed extra support had lower Raven's Progressive Matrices scores than patients without. Children with neurologic abnormalities or poor neuromotor performance (less than P10) were more likely to receive educational support (all $P<.05)$. Cerebral palsy was diagnosed in 12 patients $(10 \%), 37$ patients $(32 \%)$ had moderate neurologic abnormalities, and 19 patients $(16 \%)$ had mild neurologic abnormalities. Of the 12 patients with cerebral palsy, 8 had a history of early postoperative complications, and only 2 participants without neurologic abnormalities at the assessment experienced postoperative complications. Of the 114 children who could be examined with the ZNA ( 9 with cerebral palsy), $15 \%$ to $21 \%$ performed less than the 10th percentile on the timed motor components (Table 3). 


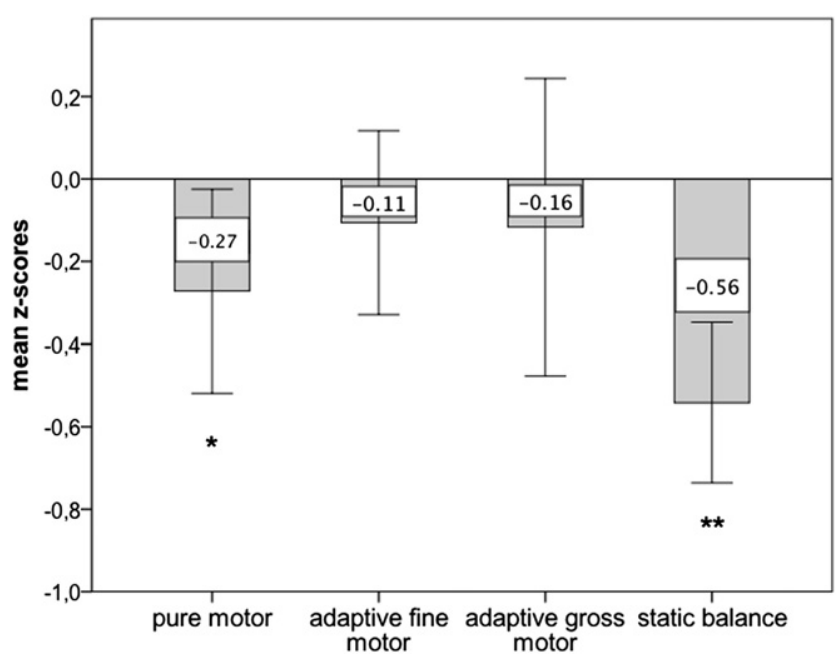

FIGURE 1. Neuromotor outcome assessed with Zurich Neuromotor Assessment (ZNA). Boxes represent the mean z-score for each motor component. The line at the $0 \mathrm{y}$ axis depicts the age-corrected norm of 0 ; the $P$ value was derived from 1-sample $t$ tests compared with normal values ( $\mathrm{n}=95$; excluding children with cerebral palsy). $* P<.01$, ** $P<.001$; error bar, $95 \%$ confidence interval.

When children with cerebral palsy were excluded, differences remained significant for the pure motor and static balance components (Figure 1). The z-scores ranged about one half standard deviation below the normal mean. Accordingly, a high rate of supportive motor therapies was reported: $34 \%$ physical therapy and $13 \%$ occupational therapy.

The patient characteristics and perioperative variables were related to the outcomes on univariate analysis. A lower Raven's Progressive Matrices standard score correlated with lower socioeconomic status, lower weight, and younger age at surgery (all $P<.01$ ). Poor motor function was associated with a greater number of bypass surgeries, lower weight at surgery, lower age at surgery (all $P<.01$ ), extracorporeal circulation time $(P<.05)$, need for postoperative resuscitation $(P=.001)$, and postoperative focal neurologic signs or EEG changes $(P<.001)$. The neurologic abnormalities at the follow-up examination correlated with lower weight at admission for surgery $(P<.05)$, length of hospital stay $(P<.001)$, and postoperative focal neurologic signs or EEG changes $(P<.001)$. Prematurity was not related to adverse outcomes in our sample. These variables were then entered into a multiple linear regression analysis to determine their independent affect for each outcome. The best predictive model (ie, greatest percentage variance explained by the combination of independent variables in the model) for each outcome variable is presented in Table 4. The intellectual outcome was only related to the socioeconomic status. Neuromotor performance was related to postoperative neurologic signs or EEG changes. Poorer performance in the pure motor component and the adaptive fine motor component was related to a longer length of stay in the hospital. The only surgical parameter that correlated with the outcome was the duration of extracorporeal circulation time, which correlated only with the adaptive fine motor component. The explained variance of outcome ranged from $4 \%$ to $19 \%$, depending on the outcome variable (Table 4).

In the multiple logistic regression analysis, the presence of cerebral palsy was the only outcome variable that was independently related to postoperative neurologic signs or EEG changes (odds ratio, 17.7; 95\% confidence interval, 2.4-129.7; $P=.005$ ). Nonmodifiable variables, such as gender, birth weight, Apgar scores, and type of CHD, were not associated with the neurodevelopmental outcomes (data not shown).

In a second set of analyses, we also included the variables cyanotic CHD, preoperative blood oxygen saturation, postoperative arrhythmias, and postoperative resuscitation. These variables have been identified as risk factors for adverse neurodevelopmental outcomes in published studies $^{5,18,19}$ but did not significantly correlate with the outcomes in our univariate analysis. None of these variables related significantly to any outcome variable on logistic regression analysis (data not shown).

\section{DISCUSSION}

In the present study, we assessed the long-term outcomes and potential risk factors in children who had undergone open heart surgery with full-flow cardiopulmonary bypass and who did not have an identified underlying genetic comorbidity. Very few studies of patients with CHD followed up to school age or adolescence have been published, ${ }^{4,5,20}$ with only 1 focusing on 8-year-old patients with CHD who underwent surgery with full-flow cardiopulmonary bypass. ${ }^{4}$ Our study highlights the persistence of developmental problems well into school age. We found that patients with CHD manifested significant intellectual and neuromotor deficits at 10 years of age, affecting school performance and daily routine.

We assessed cognitive function using the Raven's Progressive Matrices, a nonverbal intelligence test scoring general intelligence and abstract reasoning. The mean Raven's Progressive Matrices score was 89. The Raven's Progressive Matrices intelligence test correlates better with performance than with verbal intelligence. ${ }^{13}$ Thus, our findings corresponded well with the reported degree of impairment on the performance IQ, ${ }^{7,20,21}$ and to previous studies in younger children in whom the mean IQ scores were in the low normal range. ${ }^{1,22,23}$ Studies have demonstrated that the performance IQ is lower than the verbal IQ in patients with $\mathrm{CHD} .{ }^{4,5}$ We also found that motor performance was significantly affected, even when the children with cerebral palsy were excluded. The average motor performance of the total cohort was in the 
TABLE 4. Factors related to adverse neurodevelopmental outcome in children with CHD

\begin{tabular}{|c|c|c|c|c|c|}
\hline Outcome measure & Predictor variables & $P$ value (model) & $\mathbf{r}^{2}(\%$ variance $)$ & Parameter estimate & $P$ value (variable) \\
\hline \multirow[t]{2}{*}{ RPM standard score } & & .006 & 7 & & \\
\hline & Socioeconomic status & & & 2.0 & .006 \\
\hline \multirow[t]{2}{*}{ ZNA pure motor } & & .027 & 4 & & \\
\hline & Length of hospital stay & & & -0.02 & .03 \\
\hline \multirow[t]{4}{*}{ ZNA adaptive fine motor } & & $<.001$ & 19 & & \\
\hline & Length of hospital stay & & & -0.03 & .005 \\
\hline & Postoperative neurologic signs & & & -1.3 & .008 \\
\hline & Extracorporeal circulation time & & & 0.007 & .05 \\
\hline \multirow[t]{2}{*}{ ZNA adaptive gross motor } & & $<.001$ & 15 & & \\
\hline & Postoperative neurologic signs & & & -2.4 & $<.001$ \\
\hline \multirow[t]{2}{*}{ ZNA static balance } & & .013 & 17 & & \\
\hline & Postoperative neurologic signs & & & -1.2 & $<.001$ \\
\hline
\end{tabular}

Statistics: stepwise linear regression, including the following variables: socioeconomic status, number of surgeries, extracorporeal circulation time, postoperative neurologic signs (including postoperative electroencephalographic anomalies or focal neurologic symptoms), age at first surgery, resuscitation after surgery, intensive care unit stay, cyanotic CHD, hospital length of stay. CHD, Congenital heart disease; RPM, Raven's Progressive Matrices; ZNA, Zurich Neuromotor Assessment.

low-normal range, however, with a wide variation and a greater proportion of children performing at less than the 10th percentile than in the normal population. These findings are in line with the results from Karl and colleagues, ${ }^{4}$ who reported that manual dexterity and static balance were particularly affected in 8-year-old children with corrected transposition of the great arteries. Mild neurologic abnormalities were noted in nearly $50 \%$ of our patients with CHD, highlighting that such findings known from younger patients with $\mathrm{CHD}^{18}$ persist into school age and early adolescence. Because our cohort was composed of "low-risk" patients with less complex surgical procedures, the poor neurodevelopmental outcome is a somewhat unexpected finding, emphasizing the need for standardized follow-up and early intervention for all children undergoing open heart surgery for CHD. In contrast to most other studies, the children in our cohort underwent their first open heart surgery relatively late in their development, at a mean age of 1.1 years instead of in the first days or weeks of life. Although the heart defects of our patients were less severe than the those of currently operated children, we found comparable rates of neurodevelopmental impairments as did other groups., ${ }^{4,9,18,21,24}$ This might have been because of the less advanced perioperative and intraoperative care, which has progressed dramatically in recent years. ${ }^{23,24}$ Furthermore, in our study, neither the type of heart defect (cyanotic or acyanotic) nor the age at surgery, number of surgeries, or perioperative variables had a significant effect on the severity of deficits. This is in line with previous studies that also showed little effect of CHD severity on the outcomes. ${ }^{4,23-25}$ Our findings support the hypothesis that CHD might involve an increased vulnerability of the brain and cerebral perfusion alterations before birth. Apparently, clinical risk factors play a minor role in the occurrence of adverse neurodevelopmental outcomes in the absence of a complicated clinical course or intraoperative events.
Therefore, the duration of hospital stay relating to the complexity of the heart defect and the associated complications is a stronger predictor of adverse outcomes. ${ }^{26}$

Interestingly, the variables in our regression models explained $4 \%$ to $19 \%$ of the variance in outcome. This is analogous to previous studies reporting the outcomes for younger patients ${ }^{3-5}$ or with specific CHD diagnoses. ${ }^{27}$ In contrast, Majnemer and colleagues ${ }^{25}$ found that the type of CHD, duration of deep hypothermic circulatory arrest, and maternal education explained $42 \%$ of the variance in the performance IQ in a similar sample of children. One major difference between their study and ours was the use of a full-flow procedure in our population instead of the deep hypothermic circulatory arrest procedure in the study by Majnemer and colleagues. ${ }^{25}$ The use of a full-flow procedure might have reduced the influence of surgeryassociated risk factors in our study. This idea is supported by results from the study by Karl and colleagues ${ }^{4}$ in a cohort of children with transposition of the great arteries who also underwent surgery solely with full-flow cardiopulmonary bypass surgical support. In their study, the variance in the best predictive model was $13 \%$, comparable to our results. One additional difference between our findings and the studies of children ${ }^{5,21,23,25,27-29}$ predominantly treated using low-flow or circulatory arrest techniques or deep hypothermic cardiac arrest was the association of variables such as the perfusion time, gender, birth weight, and Apgar scores with neurodevelopmental outcome, which, in contrast, we could not confirm in our study. This difference might have resulted from the inclusion of infants with more severe types of CHD in the cited studies, in which additional factors, such as postnatal acute depression, might have been independent risk factors for adverse outcomes. The amount of diuresis on the third postoperative day after surgery has been described as another predictor of IQ by Sarajuuri and colleagues. ${ }^{29}$ We did not systematically assess this parameter in our cohort. 
That only the neuromotor outcome was related to the perioperative variables might indicate that motor function is more susceptible to neurologic injury during or after surgical repair. In contrast, cognitive abilities reflect global brain function and might be more determined by genetic or environmental factors. This is supported by the finding that socioeconomic status was related to intellectual outcome in our, and previous, studies of this population. ${ }^{4,5}$

The prevalence of cerebral palsy in our study population was $10 \%$. This is comparable to the prevalence described in other studies. $^{21,29}$ The association between later cerebral palsy and early postoperative neurologic complications detected in our study indicates that in these cases the neurologic event during the postoperative phase was most likely due to perioperative cerebral injury. This highlights the importance of cerebral imaging studies in patients with postoperative neurologic events.

In our study, the long-term neurodevelopmental outcomes were only weakly related to modifiable surgery-related variables and more strongly related to nonmodifiable patient and disease variables. The absence of an effect of surgery-related factors could be interpreted as an indicator of a relatively high standard of care that minimized the potentially harmful effects of the surgical procedures. One unanswered question remains which of the bypass techniques, low-flow, full-flow, or selective cerebral perfusion, can best protect our patients from brain damage and neurodevelopmental deficits. In addition, modifiable risk factors need to be identified to improve patient outcomes. In our study, the duration of hospital stay and postoperative neurologic signs were related to the motor outcome. These risk factors should be targeted by optimizing intensive care management and postoperative care.

\section{Study Limitations}

The present study had several limitations. The cohort studied underwent surgery in the mid- to late 1990s at a single center. In contrast to recent developments, surgery was performed in early childhood, and rate of postoperative neurologic complications was rather high. Furthermore, children with hypoplastic left heart syndrome did not undergo surgery at our institution at that time; thus, children with the most severe form of CHD with the greatest risk of adverse outcomes $^{21,23}$ were not included in our study. In addition, owing to the wide variety of included types of CHD, we were unable to define the outcomes for a particular heart defect. The lack of an association between CHD severity and outcome could also have resulted from the rather small sample size of our cohort. Furthermore, neither cerebral magnetic resonance imaging nor continuous EEG recordings were routinely performed, and this might have led to an underestimation of the true prevalence of cerebral injury. Five children of the 17 families who refused to participate had severe mental disabilities. Furthermore, cognitive function was assessed using Raven's Progressive
Matrices, a nonverbal intelligence test. It has been shown that Raven's Progressive Matrices Intelligence test correlates better with performance, than with verbal, intelligence. ${ }^{13}$ We thus might have overrated the intellectual level of these children by not assessing their verbal intelligence. Despite this selection bias, our results revealed considerable longterm deficits for children with CHD. Furthermore, we could not rule out that some of the participating patients with CHD might have had an unidentified genetic comorbidity because no systematic genetic workup was performed.

\section{CONCLUSIONS}

Children with CHD undergoing heart surgery with fullflow cardiopulmonary bypass are at risk of long-term intellectual and neuromotor impairments. In the present cohort, intellectual outcome was only related to socioeconomic status, but late neuromotor performance was related to the occurrence of early postoperative neurologic complications. Overall, modifiable, surgery-related factors played a minor role in the occurrence of adverse neurodevelopmental outcomes. The combination of intellectual and neuromotor deficits significantly affects educational perspectives and results in a high rate of educational support and therapies. Therefore, our findings stress the importance of routine follow-up assessment in specialized centers for children with all types of CHD who undergo cardiopulmonary bypass to provide early appropriate therapeutic intervention and parental guidance.

We thank Bigna Hertsch for conducting the study and the children and parents of the study for their participation.

\section{References}

1. Bellinger DC, Wypij D, du Duplessis AJ, Rappaport LA, Jonas RA, Wernovsky G, et al. Neurodevelopmental status at eight years in children with dextro-transposition of the great arteries: the Boston Circulatory Arrest Trial. $J$ Thorac Cardiovasc Surg. 2003;126:1385-96.

2. Gaynor JW, Nicolson SC, Jarvik GP, Wernovsky G, Montenegro LM, Burnham NB, et al. Increasing duration of deep hypothermic circulatory arrest is associated with an increased incidence of postoperative electroencephalographic seizures. J Thorac Cardiovasc Surg. 2005;130:1278-86.

3. Hovels-Gurich HH, Seghaye MC, Sigler M, Kotlarek F, Bartl A, Neuser J, et al. Neurodevelopmental outcome related to cerebral risk factors in children after neonatal arterial switch operation. Ann Thorac Surg. 2001;71:881-8.

4. Karl TR, Hall S, Ford G, Kelly EA, Brizard CP, Mee RB, et al. Arterial switch with full-flow cardiopulmonary bypass and limited circulatory arrest: neurodevelopmental outcome. J Thorac Cardiovasc Surg. 2004;127:213-22.

5. Majnemer A, Limperopoulos C, Shevell MI, Rohlicek C, Rosenblatt B, Tchervenkov C. A new look at outcomes of infants with congenital heart disease. Pediatr Neurol. 2009;40:197-204.

6. Wypij D, Newburger JW, Rappaport LA, duPlessis AJ, Jonas RA, Wernovsky G, et al. The effect of duration of deep hypothermic circulatory arrest in infant heart surgery on late neurodevelopment: the Boston Circulatory Arrest Trial. J Thorac Cardiovasc Surg. Nov 2003;126:1397-403.

7. Hovels-Gurich HH, Seghaye MC, Schnitker R, Wiesner M, Huber W, Minkenberg R, et al. Long-term neurodevelopmental outcomes in school-aged children after neonatal arterial switch operation. J Thorac Cardiovasc Surg. 2002; $124: 448-58$.

8. Fuller S, Nord AS, Gerdes M, Wernovsky G, Jarvik GP, Bernbaum J, et al. Predictors of impaired neurodevelopmental outcomes at one year of age after infant cardiac surgery. Eur J Cardiothorac Surg. 2009;36:40-7. 
9. Gaynor JW, Gerdes M, Zackai EH, Bernbaum J, Wernovsky G, Clancy RR, et al. Apolipoprotein E genotype and neurodevelopmental sequelae of infant cardiac surgery. J Thorac Cardiovasc Surg. 2003;126:1736-45.

10. Largo RH, Pfister D, Molinari L, Kundu S, Lipp A, Duc G. Significance of prenatal, perinatal and postnatal factors in the development of AGA preterm infants at five to seven years. Dev Med Child Neurol. 1989;31:440-56.

11. Landolt MA, Valsangiacomo Buechel ER, Latal B. Health-related quality of life in children and adolescents after open-heart surgery. J Pediatr. 2008;152: 349-55.

12. Raven JRJ, Court JH. Manual for Raven's Progressive Matrices and Vocabulary Scales. San Antonio: Harcourt Assessment; 2003.

13. Saklofske DH, Weiss L, Beal AL, Coalson D. The Wechsler Scales for assessing children's intelligence: past to present. In: Georgas J, Weiss L, van de Vijver FJR, Saklofske D, eds. Culture and children's intelligence: cross-cultural analysis of the WISC-III. New York: Academic Press; 2003.

14. Hajnal BL, Sahebkar-Moghaddam F, Barnwell AJ, Barkovich AJ, Ferriero DM. Early prediction of neurologic outcome after perinatal depression. Pediatr Neurol. 1999;21:788-93.

15. Sellier E, Surman G, Himmelmann K, Andersen G, Colver A, Krageloh-Mann I, et al. Trends in prevalence of cerebral palsy in children born with a birth weight of 2,500 g or over in Europe from 1980 to 1998. Eur J Epidemiol. 2010;25:635-42.

16. Largo RH, Caflisch JA, Hug F, et al. Neuromotor development from 5 to 18 years. Part 1: timed performance. Dev Med Child Neurol. 2001;43:436-43.

17. Rousson V, Gasser T, Caflisch J, Largo R. Reliability of the Zurich Neuromotor Assessment. Clin Neuropsychol. 2008;22:60-72.

18. Limperopoulos C, Majnemer A, Shevell MI, Rohlicek C, Rosenblatt B, Tchervenkov C, et al. Predictors of developmental disabilities after open heart surgery in young children with congenital heart defects. J Pediatr. 2002;141: $51-8$.

19. Massaro AN, El-Dib M, Glass P, Aly H. Factors associated with adverse neurodevelopmental outcomes in infants with congenital heart disease. Brain Dev. 2008;30:437-46.
20. Ballweg JA, Wernovsky G, Gaynor JW. Neurodevelopmental outcomes following congenital heart surgery. Pediatr Cardiol. 2007;28:126-33.

21. Mahle WT, Clancy RR, Moss EM, Gerdes M, Jobes DR, Wernovsky G. Neurodevelopmental outcome and lifestyle assessment in school-aged and adolescent children with hypoplastic left heart syndrome. Pediatrics. 2000;105: 1082-9.

22. Newburger JW, Wypij D, Bellinger DC, du Plessis AJ, Kuban KC, Rappaport LA, et al. Length of stay after infant heart surgery is related to cognitive outcome at age 8 years. J Pediatr. 2003;143:67-73.

23. Gaynor JW, Gerdes M, Nord AS, Bernbaum J, Zackai E, Wernovsky G, et al. Is cardiac diagnosis a predictor of neurodevelopmental outcome after cardiac surgery in infancy? J Thorac Cardiovasc Surg. 2010;140:1230-7.

24. Miatton M, De Wolf D, Francois K, Thiery E, Vingerhoets G. Neuropsycholog ical performance in school-aged children with surgically corrected congenital heart disease. J Pediatr. 2007;151:73-8. 78 e71.

25. Majnemer A, Limperopoulos C, Shevell M, Rohlicek C, Rosenblatt B Tchervenkov C. Developmental and functional outcomes at school entry in children with congenital heart defects. J Pediatr. 2008;153:55-60.

26. Rodriguez FH III, Moodie DS, Parekh DR, Franklin WJ, Morales DL, Zafar F, et al. Outcomes of hospitalization in adults in the United States with atrial septal defect, ventricular septal defect, and atrioventricular septal defect. Am J Cardiol. 2011;108:290-3

27. Mahle WT, Visconti KJ, Freier MC, Kanne SM, Hamilton WG, Sharkey AM, et al. Relationship of surgical approach to neurodevelopmental outcomes in hypoplastic left heart syndrome. Pediatrics. 2006;117:e90-7.

28. McQuillen PS, Barkovich AJ, Hamrick SE, Perez M, Ward P, Glidden DV, et al Temporal and anatomic risk profile of brain injury with neonatal repair of congenital heart defects. Stroke. 2007;38(2 Suppl):736-41.

29. Sarajuuri A, Jokinen E, Puosi R, Eronen M, Mildh L, Mattila I, et al. Neurodevelopmental and neuroradiologic outcomes in patients with univentricular heart aged 5 to 7 years: related risk factor analysis. J Thorac Cardiovasc Surg. 2007; 133:1524-32. 